\title{
Acute Arterial Embolization Following Total Knee Arthroplasty: A Report of Two Cases and Literature Review
}

\author{
Akute arterielle Embolie nach einer Knie-Totalendoprothese: \\ Ein Bericht über zwei Fälle und Literaturübersicht
}

\section{(ㄷ) (2) (1) (-)}

Authors

Chen Wang ${ }^{1,2}{ }^{\circledR}$, Xin Zhang ${ }^{1}$, Haoran Yu ${ }^{1}$, Wendan Cheng ${ }^{1}$

Institute

1 Department of Orthopaedic Surgery, The Second Hospital of Anhui Medical University, Hefei, China

2 Second Clinical Medical College, Anhui Medical University (12485), Hefei, China

Key words

total knee arthroplasty, acute arterial thrombosis, thrombolysis, thrombectomy, case report

\section{Schlüsselwörter}

Kniearthroplastik insgesamt, akute arterielle Thrombose, Thrombolyse, Thrombetomie, Bericht des Falles

received 1.8 .2021

accepted after revision $\quad 3.11 .2021$

published online

Bibliography

Z Orthop Unfall

DOI 10.1055/a-1714-9483

ISSN 1864-6697

(C) 2021. The Author(s).

This is an open access article published by Thieme under the terms of the Creative Commons Attribution-NonDerivative-NonCommercial-License, permitting copying and reproduction so long as the original work is given appropriate credit. Contents may not be used for commercial purposes, or adapted, remixed, transformed or built upon. (https://creativecommons.org/licenses/by-nc-nd/4.0/).

Georg Thieme Verlag KG, Rüdigerstraße 14,

70469 Stuttgart, Germany

Corresponding address

Wendan Cheng

Department of Orthopaedic Surgery

The Second Hospital of Anhui Medical University

No.678 Furong Road

230601 Hefei, China

sunyccc@126.com

\section{ABSTRACT}

Acute arterial embolization is a rare but serious complication following total knee arthroplasty (TKA). So far, the general consensus for this situation is that revascularization must be performed immediately, but the specific treatment is still controversial. We report two cases of popliteal artery (PA) embolization caused by acute arterial thrombosis following TKA. Both patients suffered the loss of sensation and movement of the right lower limb and disappearance of dorsalis pedis artery pulsation after operation. Angiography showed PA embolization. One of the patients received thrombolytic therapy, but he developed a large area of infection and necrosis of the right calf muscle and required multiple debridement and skin grafting procedures after successful thrombolysis. The other patient underwent thrombectomy, vascular reconstruction, and prophylactic fasciotomy, and some foot numbness and slight extensor weakness remained after the operation. The authors suggest that surgeons should pay adequate attention to highrisk patients with TKA. Medical history and physical examination should be carefully collected before operation. The surgical procedure should be performed accurately and gently, and limb sensation and blood circulation should be carefully observed after operation. If foot sensation is abnormal and arterial pulsation is weakened, necessary examinations (Doppler ultrasound and arteriography) should be carried out immediately. Once diagnosed with arterial thrombosis, the blood supply should be restored immediately. If the diagnosis is delayed for more than 6 hours, prophylactic fasciotomy may be required as a treatment to avoid adverse consequences.

\section{ZUSAMMENFASSUNG}

Die akute arterielle Embolie ist eine seltene, aber schwerwiegende Komplikation nach einer Knie-Totalendoprothese (KnieTEP). Es besteht ein allgemeiner Konsens darüber, dass in dieser Situation sofort eine Revaskularisation durchgeführt werden muss, aber die spezifische Behandlung ist immer noch umstritten. Wir berichten über zwei Fälle von Embolien der Kniekehlenarterie, die durch eine akute arterielle Thrombose nach Knie-TEP verursacht wurden. Bei beiden Patienten kam es nach der Operation zu einem Gefühls- und Bewegungsverlust der rechten unteren Extremität und einer Pulsations- 
schwächung der Arteria dorsalis pedis; eine Angiografie zeigte eine Embolie der Arteria poplitea. Einer der Patienten erhielt eine Thrombolysetherapie, entwickelte jedoch eine großflächige Infektion und Nekrose des rechten Wadenmuskels und benötigte nach erfolgreicher Thrombolyse ein mehrfaches Débridement und Hauttransplantationen. Bei dem anderen Patienten wurde eine Thrombektomie, eine Gefäßrekonstruktion und eine prophylaktische Fasziotomie durchgeführt; nach der Operation blieben ein Taubheitsgefühl im Fuß und eine leichte Streckschwäche zurück. Die Autoren empfehlen Chirurgen, Hochrisikopatienten mit Knie-TEP eine angemessene Aufmerksamkeit zu widmen. Vor der Operation sind eine sorgfältige
Anamnese und körperliche Untersuchung erforderlich. Der chirurgische Eingriff sollte präzise und schonend durchgeführt werden, nach der Operation sind das Gefühl der Gliedmaßen und die Blutzirkulation aufmerksam zu beobachten. Bei abnormalem Fußgefühl und schwacher arterieller Pulsation sollten umgehend erforderliche Untersuchungen (Doppler-Ultraschall und Arteriografie) durchgeführt werden. Wenn eine arterielle Thrombose diagnostiziert wurde, muss die Blutversorgung sofort wiederhergestellt werden. Verzögert sich die Diagnose um mehr als 6 Stunden, kann eine prophylaktische Fasziotomie erforderlich sein, um nachteilige Folgen zu vermeiden.

\section{Introduction}

The increase in life expectancy and an aging population have led to a sharp increase in the number of patients with knee joint diseases. Total knee arthroplasty (TKA) has become the most important and effective method for the treatment of some serious knee joint diseases [1]. Arterial complications associated with TKA are rare, with a reported incidence of only 0.03 to $0.17 \%[2,3,4]$. Less than 100 cases have been reported, but these include arterial transection, aneurysm, arteriovenous fistula, and thrombus embolization. Acute arterial embolization is an extremely rare complication but if it is not treated in time it may lead to severe consequences. It has been reported that the mortality rate of these complications is as high as $7 \%$, and the amputation rate as high as $42 \%[5,6]$. At present, there is no consensus on the best treatment for arterial thrombosis following TKA [7]. There are two main types of clinical treatment: endovascular treatment and open surgery. Endovascular treatment includes balloon angioplasty, thrombus aspiration, thrombin injection, stent implantation, and coil embolization. Open surgery includes end-to-end anastomosis, Fogarty catheter connection and one-stage repair, vascular graft placement, or bypass surgery [8, 9]. The two cases reported here were treated by two different approaches, and the prognosis of the patients was also different. The cases are reported below.

\section{Case Reports}

\section{Case 1}

A 62-year-old male patient had pain in his right knee for 10 years that had been aggravated for the previous year. He had no specific medical history or history of peripheral vascular disease. Physical examination on admission revealed tenderness on the inside of the right knee joint, limited movement, with a range of motion $20^{\circ}$ extension to $90^{\circ}$ flexion, normal feeling of the right lower limb, and normal muscle strength. An X-ray showed narrowing of the right knee joint space with obvious local hyperosteogeny ( Fig. 1a, b). The admission diagnosis was right knee osteoarthritis (Kellgren-Lawrence [KL] grade VI). Doppler ultrasound showed moderate arteriosclerosis in both lower extremities. On the 4th day of admission, the patient underwent a right TKA. The surgery lasted 90 minutes, using a tourniquet for 60 minutes and pressure of $260 \mathrm{mmHg}$. Before the prosthesis was installed, a periarticular cocktail was injected around the joint capsule. No popliteal artery (PA) hemorrhage was found during the operation, and the dorsalis pedis artery pulsed well after operation. The patient received routine anticoagulant therapy (subcutaneous injection of low-molecular-weight heparin $3200 \mathrm{U}$, once per day) and appropriate antiinflammatory treatment. On the first day after operation (20 hours after operation), the patient still felt numb and dull in the lower part of the right leg, and had difficulty lifting the straight leg out of bed. The pulsation of the right foot dorsal artery was good, but he was unable to move his foot. Considering that these symptoms may be caused by preoperative nerve block anesthesia, no special treatment was given. Postoperative X-ray examination showed that the joint prosthesis was in a good position ( $\triangleright$ Fig. 1c, d). On the second day after operation, the skin temperature of the right foot was obviously decreased, and the patient reported worsening pain in the right foot. Distal movement and sensation were lost, and the pulse of the dorsalis pedis artery was weak. Ultrasonography immediately indicated the formation of an atherosclerotic plaque in the right lower limb and local embolization of the right PA. After the diagnosis was confirmed by arterial angiography ( $\triangleright$ Fig. 2a), arterial catheter thrombolytic therapy of the right lower limb was performed immediately. The right PA was basically unobstructed after thrombolytic therapy ( $\triangleright$ Fig. 2 b, c). On the second day after thrombolysis, the skin temperature of the right foot had recovered and the right dorsalis pedis artery pulsed well. However, sensation and movement of the right leg were not restored, and there was slight swelling. Arteriography was performed again and indicated the formation of an arterial fistula ( $\triangleright$ Fig. $2 \mathrm{~d}$ ). The blood vessels and nerves of the popliteal fossa were explored immediately. During the operation, it was found that the PAs and veins were unobstructed, and there was no arteriovenous fistula, only one small artery (diameter $1 \mathrm{~mm}$ ) with active bleeding, which had formed a hematoma with a volume of approximately $15 \mathrm{~mL}$, oppressing the origin of the tibial nerve. After clearance, no obvious injury was found of the tibial nerve or the common peroneal nerve. However, the tension of the lateral osteofascial compartment of the leg was increased, and the muscle color was slightly pale, oppressing the common peroneal nerve. After incision and decompression, the color of the muscle recovered, the color of 

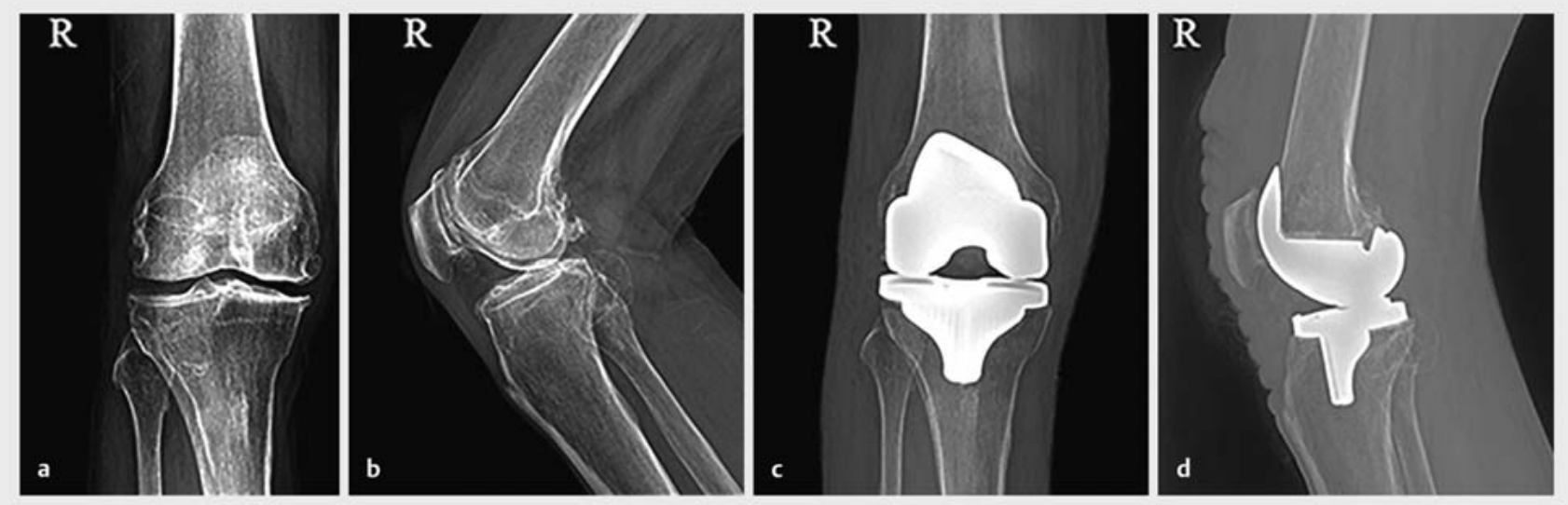

- Fig. 1 X-ray of the right knee joint of the first patient. a, b Preoperative radiographs showed stenosis of the right knee joint and osteophyte hyperplasia. The letter $\mathrm{R}$ stands for the right knee joint. c, $\mathbf{d}$ Postoperative radiographs showed that each implant was installed in the proper position. The letter $R$ stands for the right knee joint.
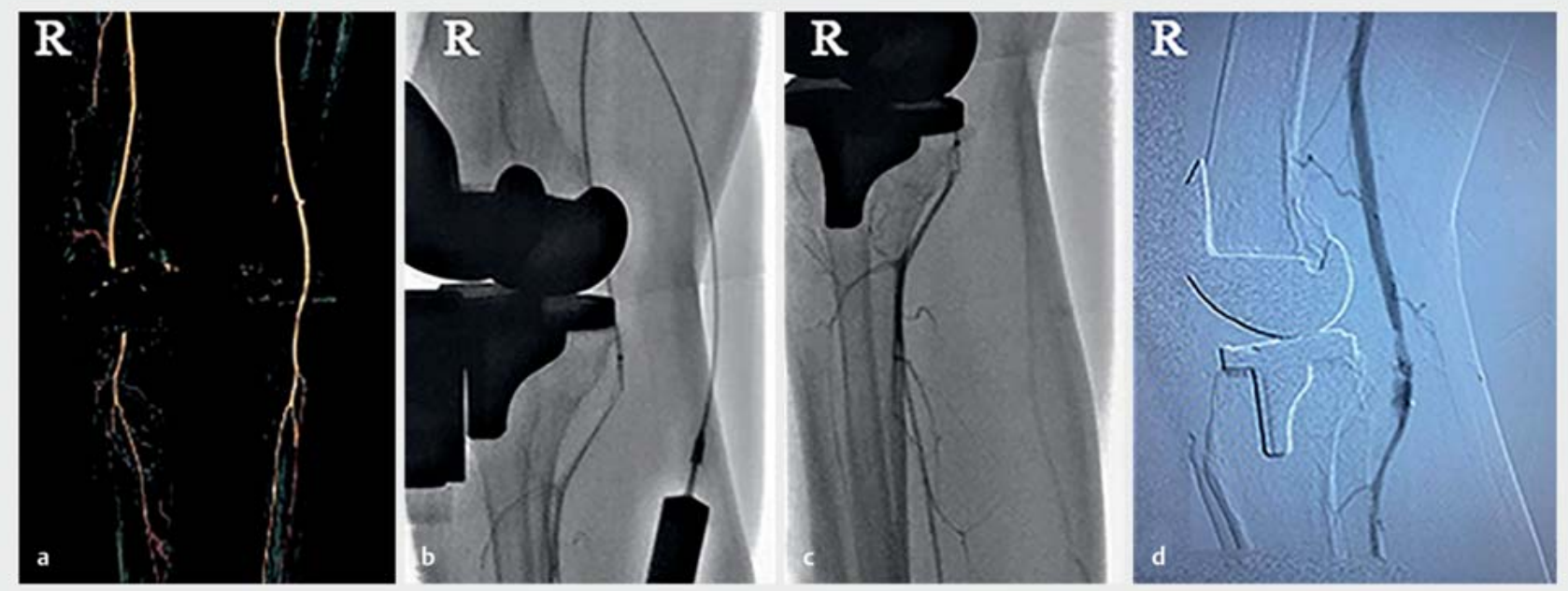

- Fig. 2 Arterial angiography of the first patient. a Local segmental embolization of the right PA. The letter R stands for the right knee joint. b Thrombolysis of the ductus arteriosus was performed. The letter $\mathrm{R}$ stands for the right knee joint. $\mathrm{c}$ The right PA was basically unobstructed. The letter $\mathrm{R}$ stands for the right knee joint. $\mathrm{d}$ Arteriovenous fistula was formed. The letter $\mathrm{R}$ stands for the right knee joint.

the medial muscle group was good, and no further incision of the medial lateral osteofascial chamber was performed. One week later, there was no significant improvement in calf movement or sensation. When preparing to suture the incision, it was found that there was a large area of ischemic necrosis in the patient's right leg muscle, and only the lateral residual muscle survived. The patient underwent several rounds of debridement and skin grafting operations over the following 4 months. One year after discharge, the patient had complete loss of sensation in his right foot, foot drop deformity, and difficulty in walking ( $\triangleright$ Fig. 3). Ultrasound showed that the blood vessels of the right lower extremities were unobstructed, and the PA thrombus had disappeared.

\section{Case 2}

An 84-year-old woman had suffered from right knee pain with movement restriction for 20 years due to osteoarthritis. She had a history of previous left knee arthroplasty, hypertension, hyperlipidemia, diabetes, coronary heart disease, two percutaneous coronary interventions (PCls), right lower limb acute lymphangitis, and long-term smoking. The admission physical examination revealed tenderness on the inside of the right knee joint, limited movement, range of motion from $40^{\circ}$ extension to $70^{\circ}$ flexion, normal feeling in the right lower limb, and normal muscle strength. X-ray 

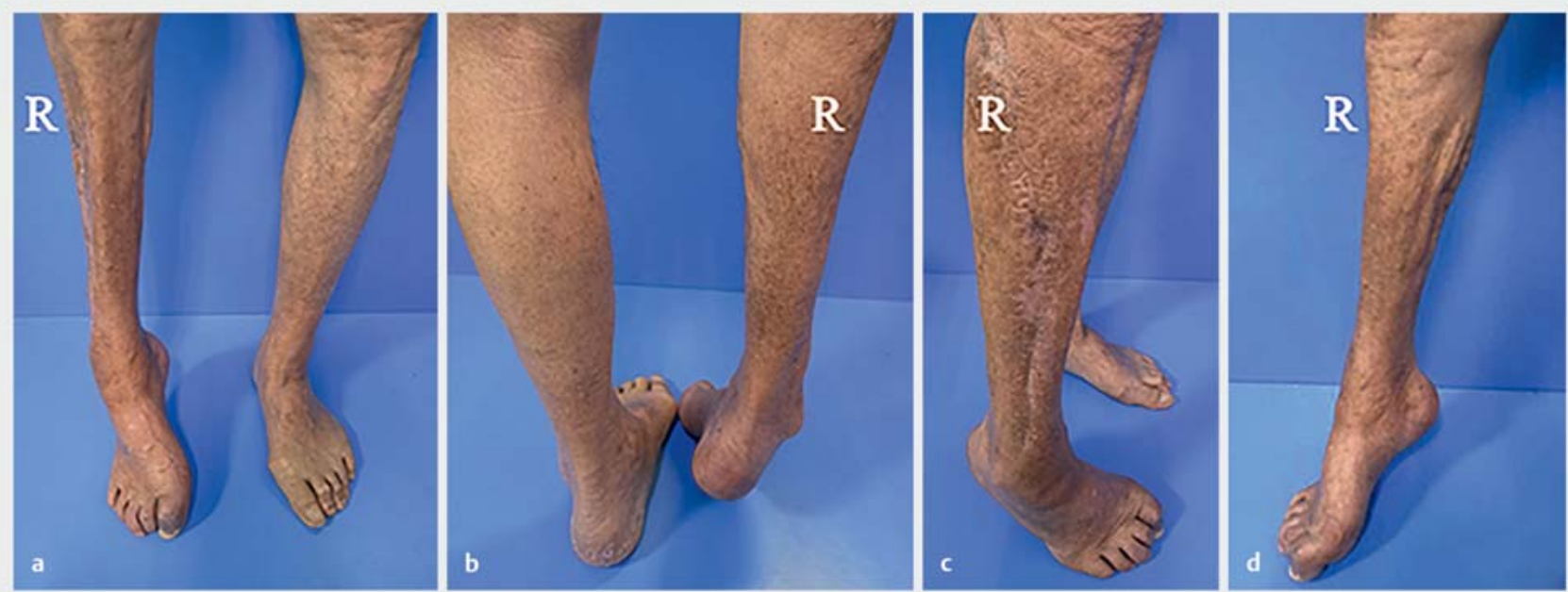

- Fig. 3 Pictures 1 year after operation of the first patient. a-d The skin of the right leg healed well, but sensation and movement of the lower leg were completely lost, the right foot was drooping and inverted, and the toe contracture was deformed. The letter $\mathrm{R}$ stands for the right calf.
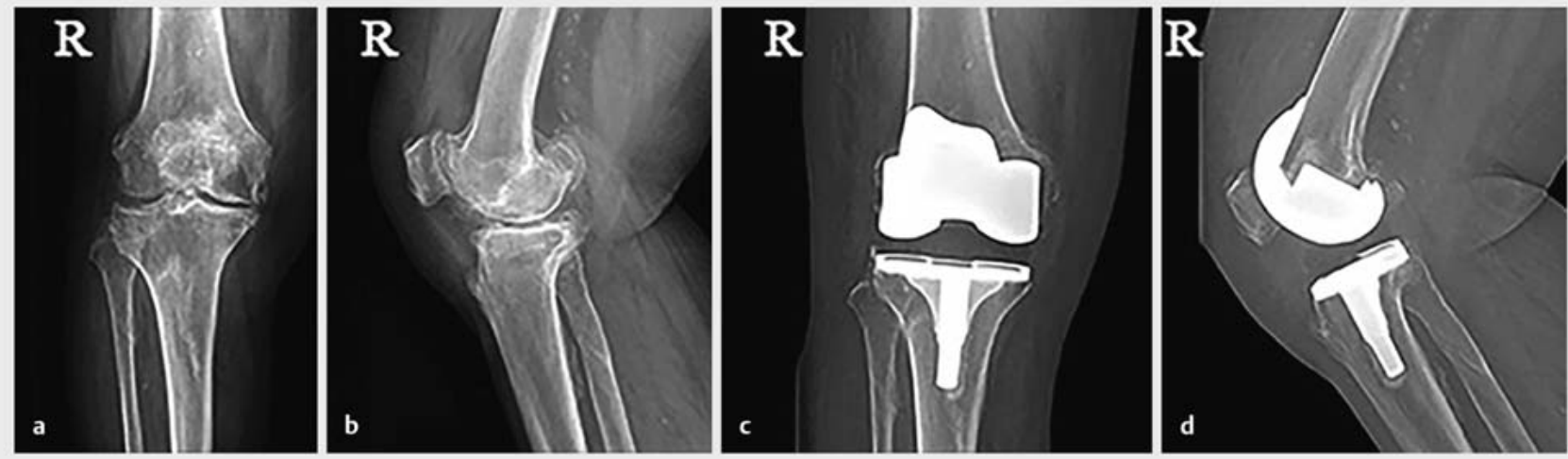

- Fig. 4 X-ray of the right knee joint of the second patient. a, b Preoperative X-ray showed stenosis of the medial space of the right knee joint and osteophyte hyperplasia. The letter $\mathrm{R}$ stands for the right knee joint. c, $\mathrm{d}$ Postoperative radiographs showed that the position of the joint prosthesis was good. The letter $R$ stands for the right knee joint.

showed narrowing of the space of the right knee joint and obvious local hyperosteogeny ( $\triangleright$ Fig. 4 a, b). The admission diagnosis was right knee osteoarthritis ( $\mathrm{KL}$ grade VI). Doppler ultrasound showed atherosclerotic plaque formation in both lower extremities. On the 9th day of admission, the patient underwent a right TKA, which lasted 120 minutes, using a tourniquet for 80 minutes and pressure of $260 \mathrm{mmHg}$. Before the prosthesis was installed, we injected a periarticular cocktail around the joint capsule. No PA hemorrhage was found during the operation. The dorsalis pedis artery pulsed well after operation, and the skin temperature of the right ankle was slightly reduced. The patient received routine anticoagulant therapy (subcutaneous injection of low-molecularweight heparin $3200 \mathrm{U}$, once per day) and appropriate anti-inflammatory treatment. On the 1 st day after operation (16 hours after operation), the skin temperature of the right foot was still lower than that of the left, but normal sensory activity of the right foot and pulsation of the dorsalis pedis artery were observed. X-ray examination showed that the joint prosthesis was in a good position ( $\vee$ Fig. 4c, d). On the 2 nd day after operation, the pain in the right leg was aggravated and the right foot was pale and cold. The right ankle and toe could not be extended, sensation below the ankle was lost, and the pulsation of the dorsalis pedis artery had disappeared. The patient was immediately examined by vascular ultrasound and arterial angiography of both lower extremities, and the cause was confirmed as PA embolization ( Fig. 5). Emergency PA incision and thrombectomy were performed. During the operation, it was found that the P3 segment of the PA was locally embolized for a distance of approximately $3 \mathrm{~cm}$. The arterial wall was 

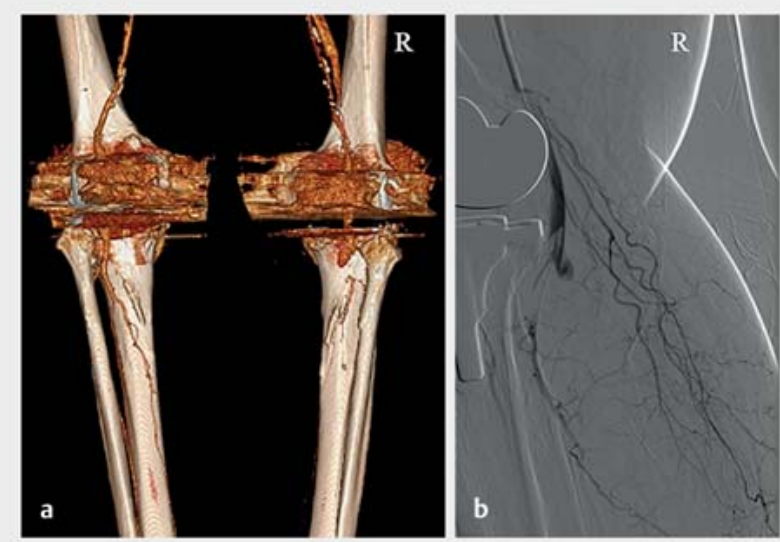

- Fig. 5 Arterial angiography of the second patient. a, b Arterial angiography showed segmental local embolization at the distal end of the right PA. The letter $\mathrm{R}$ stands for the right knee joint.

stripped, and the lesion was opened with a Fogarty catheter. Needle puncture marks on the wall of the PA were found during the operation, but there was no formation of blood scabs. Vascular repair and reconstruction and preventive incision and decompression of the osteofascial compartment of the leg showed that muscle vitality was good. After the operation, the patient was given routine symptomatic support treatment comprising anticoagulation, tube dilatation, and anti-infection. An ultrasound showed that the blood vessels of the right lower extremities were unobstructed. At discharge (45 days after operation), the patient's right leg was slightly swollen, but the incision had healed well and the dorsalis pedis artery pulsed well. The patient was able to walk with the assistance of a walker, but local skin on the right foot was numb and sensation was significantly reduced. The right ankle and right toe could not be stretched backwards, and the right foot was prolapsed. One year after using an ankle orthosis to correct the right ankle, the motor function of the right ankle and toe had recovered, and the patient was able to walk normally ( $\triangleright$ Fig. 6) but there was still some residual numbness and sensory abnormalities in the dorsum of the foot.

\section{Discussion}

There are relatively few reports of arterial complications following TKA, most of which occur in patients with a history of peripheral vascular disease [10]. High-risk patients are those with intermittent claudication, pain at rest, previous ischemic ulcers, previous vascular surgery, pedal pulse loss, or asymmetry [11]. Therefore, patients with peripheral arterial disease need to be evaluated in detail before operation. Among them, history collection and physical examination are not only the most important part of the preoperative evaluation, but also the basis of diagnosis and treatment. The surgeon should carefully inquire about the patient's past medical history and previous course of treatment, pay attention to the patient's skin damage, check the muscle strength of both lower limbs, perform a sensory evaluation, check the pa-
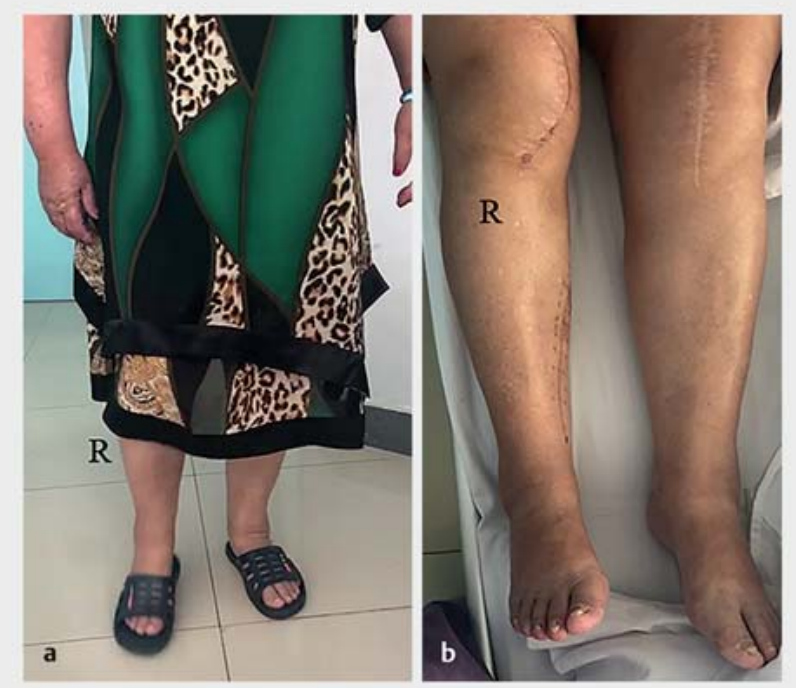

- Fig. 6 Pictures 1 year after operation of the second patient. a The patient was able to walk normally. The letter $\mathrm{R}$ stands for the right knee joint. $b$ The back of the right foot stretched forcefully and there was no foot prolapse deformity. The letter R stands for the right knee joint.

tient's peripheral vascular status, measure the ankle-brachial index $(\mathrm{ABI})$, and check the arterial pulsation (anterior tibial artery, posterior tibial artery, and dorsalis pedis artery). Supplementary evaluation of medical history and physical examination are carried out through an appropriate diagnostic auxiliary examination. For patients with blood supply problems, noninvasive vascular examination (Doppler ultrasound) should be performed. If the result of the examination is abnormal, a vascular surgeon should be consulted to assess the risk of operation. In the two patients reported this time, preoperative lower limb vascular ultrasound suggested the formation of atherosclerotic plaques in both lower limbs, which may rupture due to mechanical pressure, leading to arterial embolism and dysfunction. The second patient reported above had hypertension, diabetes, coronary heart disease, two PCI histories, and a long-term smoking history. These are risk factors for arterial embolization.

For patients with peripheral artery disease, the TKA operation should be performed gently to avoid vascular injury, paying particular attention to the use of a tourniquet [12]. The use of a tourniquet during TKA can effectively reduce the amount of blood loss and reveal the surgical visual field more clearly [13]. However, long-term low perfusion may cause local damage to the distal skin, nerves, and blood vessels, which is conducive to thrombosis. Most patients suffering from osteoarthritis are elderly and have associated atherosclerosis. Their blood vessels have become calcified and inelastic, and the mechanical pressure of the tourniquet may lead to intimal tear and plaque fragmentation, resulting in embolization [14]. Matziolis et al. [15] reported a case of arterial embolization caused by the use of a tourniquet for only approximately 10 minutes during TKA. This demonstrates that a calcified plaque 
is fragile and even short-term use of a tourniquet can cause plaque rupture. Some studies have shown that TKA without a tourniquet is safe and beneficial for early rehabilitation in patients with vascular diseases of the lower extremities [13]. The two patients described in this report showed atherosclerosis by color Doppler ultrasound before surgery, but a tourniquet was still used during the operation. This may have caused arterial intima tearing and plaque damage, leading to arterial thrombosis. Therefore, for patients with peripheral artery disease, attention should be paid to shortening the duration of use of a tourniquet or not using a tourniquet at all. If intraoperative vascular injury is suspected (such as excessive bleeding, swelling of the popliteal fossa, or disappearance of peripheral arterial pulsation), the tourniquet should be deflated before implanting the prosthesis in order to fully evaluate the vascular condition. Before the incision is closed, the tourniquet should be loosened to ensure adequate hemostasis. If the tourniquet is relaxed after suturing the skin, any arterial injury may be covered up.

The curative effect of treatment for arterial embolization following TKA is not good, and a high amputation rate and high mortality have been described in previous reports [16]. The key to a good prognosis is early diagnosis and effective treatment [17]. In the study by Calligaro et al. [18], 44\% of arterial injuries in joint replacement surgery were not diagnosed on the day of surgery. Typical ischemic symptoms (such as pain and kinesthesia) are often masked under anesthesia. Artifacts caused by joint prostheses can interfere with computed tomography (CT) and magnetic resonance angiography (MRA) results. The possibility of false negatives is also a problem with Doppler ultrasound. These facts have brought great challenges to the diagnosis and treatment of arterial embolization by surgeons [19]. No PA hemorrhage was found during the operation in these two patients, and the dorsalis pedis artery pulsed well after operation. However, it could not be completely ruled out that the thrombosis occurred at the time of surgery. If patients had undergone ankle/brachial index (ABI) measurements in the recovery room, problems might have been detected earlier. The two cases reported here both developed pain and sensory disturbances on the 1st day after surgery, which were believed to be caused by surgical wound pain and preoperative nerve block. This situation therefore did not attract attention until the 2 nd day after surgery. Therefore, we believe that for all postoperative patients in the recovery room, particularly those who have received regional anesthesia and are unconscious for several hours after operation, their circulation should be carefully evaluated in order to take more urgent intervention measures. In addition, for patients with peripheral artery disease, it is necessary to check the patient's arterial pulsation of the lower extremities and measure $A B I$ before and immediately after operation. Once the operation is completed, the pulse of the affected limb and $A B I$ measurement should be checked and checked again in the anesthesia recovery room, and the vascular status should be reported for at least 3 consecutive days after operation. The findings should be compared with the preoperative vascular examination and, if any differences are found, Doppler ultrasound should be used to identify them immediately, and then arterial angiography should be performed to determine the precise location of the lesion. If the distal pulse cannot be found, a vascular surgeon should evaluate the patient immediately. When patients experience pain after surgery, doctors should fully understand the nature of the pain. Due to arterial spasm at the embolization site and the sudden increase in proximal arterial pressure, pain often starts at the obstructed plane and extends to the distal end. Surgeons should pay attention to distinguish such pain from the wound pain, and not to blindly provide pain relief, which can cover up the condition.

Due to the rarity of this complication, its treatment plan should depend on the specific situation [20]. Two commonly used clinical treatment methods are interventional thrombolysis and surgical thrombectomy $[21,22]$. The latest research shows that for the early treatment of acute limb ischemia, there is no overall difference in amputation rate and mortality between interventional thrombolysis and surgical thrombectomy [8]. No matter which kind of treatment is chosen, immediate revascularization and reducing the time of limb ischemia is the key to successful treatment [7, 23]. It is generally believed that more than 4-6 hours of ischemia will cause irreversible muscle and nerve damage [24]. Therefore, some scholars advocate that all patients with suspected limb ischemia for more than 6 hours or muscle swelling during exploration should undergo fasciotomy [25]. Of the two patients we reported, the first patient chose thrombolytic therapy, and the arterial blood supply was restored after the operation, but the osteofascial compartment was not prevented from opening, thus allowing large areas of muscle infection and necrosis, which led to catastrophic consequences. This caused the patient a huge financial burden as well as psychological pressure. The second patient developed similar symptoms. After learning the lesson of the first patient, we performed a timely operation to remove the embolus and create an adequate osteofascial compartment to prevent incision and decompression in the second patient. The prognosis of the second patient was significantly better than that of the first patient. Based on comprehensive considerations, we believe that when acute arterial embolization occurs following TKA, if the ischemia time exceeds 6 hours, preventive incision and tension reduction are very important for functional recovery of the limbs after operation.

\section{Conclusion}

Acute arterial embolization following TKA is a rare but very serious complication. When high-risk patients undergo TKA, their medical history should be taken and a physical examination should be carefully performed before the operation, the intraoperative procedures should be precise and gentle, the use of tourniquets should be avoided as much as possible, and the limb sensation and blood supply should be carefully observed after the operation. Physical signs such as limb ischemia and disappearance of pulse must be recognized as soon as possible, and necessary examinations (Doppler ultrasound and arterial angiography) should be performed immediately. Once the diagnosis is confirmed, we recommend working closely with vascular surgeons to carry out revascularization immediately. If the diagnosis is delayed for more than 6 hours, prophylactic fasciotomy may be required as a treatment to avoid adverse consequences. 
Fördermittel

S202007d07050015. I Anhui Provincial Department of Science and Technology | http://dx.doi.org/10.13039/501100010816

Conflict of Interest

The authors declare that there is no conflict of interest.

\section{References}

[1] Park B], Cho HM, An KY et al. Acute Arterial Occlusion Following Primary Total Knee Arthroplasty. Knee Surg Relat Res 2018; 30: 84-88. doi:10.5 792/ksrr.17.024

[2] Behnke NM, Cui Q, Orndorff D. Late presentation of a mycotic popliteal artery pseudoaneurysm in the setting of a revised total knee arthroplasty complicated by both prior infection and periprosthetic fracture: a case report. Ann Vasc Surg 2007; 21: 519-524. doi:10.1016/j.avsg.2007.01.0 09

[3] Inomata K, Sekiya I, Otabe K et al. Acute arterial occlusion after total knee arthroplasty: a case report. J Clin Case Rep 2017; 5: 1376-1380. doi:10.1002/ccr3.1075

[4] Rand JA. Vascular complications of total knee arthroplasty. Report of three cases. J Arthroplasty 1987; 2: 89-93. doi:10.1016/s0883-5403(87) 80014-1

[5] Abularrage C], Weiswasser JM, Dezee KJ et al. Predictors of lower extremity arterial injury after total knee or total hip arthroplasty. J Vasc Surg 2008; 47: 803-808. doi:10.1016/j.jvs.2007.11.067

[6] Kehagias E, loannou CV, Kontopodis N et al. Intraoperative Endovascular Stent-graft Repair of a Popliteal Artery Laceration and Occlusion during Total Knee Arthroplasty. Ann Vasc Surg 2015; 29: 1453-1459. doi:10.1 016/j.avsg.2015.04.081

[7] Darwood R, Berridge DC, Kessel DO et al. Surgery versus thrombolysis for initial management of acute limb ischaemia. Cochrane Database Syst Rev 2018(8): CD002784. doi:10.1002/14651858.CD002784.pub3

[8] Olinic DM, Stanek A, Tataru DA et al. Acute Limb Ischemia: An Update on Diagnosis and Management. J Clin Med 2019; 8: 1215. doi:10.3390/jcm 8081215

[9] Sundaram K, Udo-Inyang I, Mont MA et al. Vascular Injuries in Total Knee Arthroplasty: A Systematic Review and Meta-Analysis. JBJS Rev 2020; 8: e51. doi:10.2106/JBJS.RVW.19.00051

[10] Bayne CO, Bayne O, Peterson M et al. Acute arterial thrombosis after bilateral total knee arthroplasty. J Arthroplasty 2008; 23: 1231-1239. doi:10.1016/j.arth.2007.11.012
[11] Smith DE, Mcgraw RW, Taylor DC et al. Arterial complications and tota knee arthroplasty. J Am Acad Orthop Surg 2001; 9: 253-257. doi:10.543 5/00124635-200107000-00005

[12] Runge $\mathrm{N}$, Hollifield $\mathrm{L}$, Arnold $\mathrm{M}$ et al. Acute popliteal thrombus following total knee arthroplasty: A case report. Medicine (Baltimore) 2020; 99: e22500. doi:10.1097/MD.0000000000022500

[13] Zhou K, Ling $\mathrm{T}$, Wang $\mathrm{H}$ et al. Influence of tourniquet use in primary total knee arthroplasty with drainage: a prospective randomised controlled trial. J Orthop Surg Res 2017; 12: 172. doi:10.1186/s13018-017-0683-z

[14] He R, Yang L. Acute arterial occlusion in the midpiece of femoral artery following total knee arthroplasty: Report of one case. Chin J Traumatol 2016; 19: 116-118. doi:10.1016/j.cjtee.2016.01.007

[15] Matziolis G, Perka C, Labs K. Acute arterial occlusion after total knee arthroplasty. Arch Orthop Trauma Surg 2004; 124: 134-136. doi:10.1007| s00402-003-0602-0

[16] Avisar E, Elvey MH, Bar-Ziv Y et al. Severe vascular complications and intervention following elective total hip and knee replacement: A 16-year retrospective analysis. J Orthop 2015; 12: 151-155. doi:10.1016/j.jor.2 015.01 .008

[17] Li Z, Xiang S, Bian YY et al. Diagnosis and Treatment of Arterial Occlusion after Knee Arthroplasty: The Sooner, the Better. Orthop Surg 2019; 11: 366-372. doi:10.1111/os.12494

[18] Calligaro KD, Dougherty MJ, Ryan S et al. Acute arterial complications associated with total hip and knee arthroplasty. J Vasc Surg 2003; 38: 1170-1177. doi:10.1016/s0741-5214(03)00918-2

[19] Weiss CR, Azene EM, Majdalany BS et al. ACR Appropriateness Criteria Sudden Onset of Cold, Painful Leg. J Am Coll Radiol 2017; 14: S307S313. doi:10.1016/j.jacr.2017.02.015

[20] Ebben HP, Jongkind V, Wisselink W et al. Catheter Directed Thrombolysis Protocols for Peripheral Arterial Occlusions: a Systematic Review. Eur J Vasc Endovasc Surg 2019; 57: 667-675. doi:10.1016/j.ejvs.2018.11.018

[21] Golchehr B, Lensvelt MM, Fritschy WM et al. Outcome of thrombolysis and thrombectomy for thrombosed endografts inserted in the superficial femoral artery for occlusive disease. J Endovasc Ther 2013; 20: 836843. doi:10.1583/13-4374MR.1

[22] Melnic CM, Heng M, Lozano-Calderon SA. Acute Surgical Management of Vascular Injuries in Hip and Knee Arthroplasties. J Am Acad Orthop Surg 2020; 28: 874-883. doi:10.5435/JAAOS-D-19-00697

[23] Reynolds A, Sandstrom A, Jha PK. Totally Endovascular Management of Popliteal Artery Occlusion and Pseudoaneurysm Formation after Total Knee Replacement. Ann Vasc Surg 2017; 38: 313-316. doi:10.1016/j.avs g.2016.05.100

[24] Karanam L, Busireddy NR, Baddam SR et al. Acute thrombotic occlusion after total knee arthroplasty: Role of endovascular management. J Clin Orthop Trauma 2018; 9: 121-124. doi:10.1016/j.jcot.2016.12.010

[25] Grigorian A, Wilson SE, Kabutey NK et al. Decreased National Rate of below the Knee Amputation in Patients with Popliteal Artery Injury. Ann Vasc Surg 2019; 57: 1-9. doi:10.1016/j.avsg.2018.07.002 